\title{
Espiritualidades feministas: Relações de gênero e padrões de família entre adeptos da wicca e do candomblé no Brasil
}

Feminist Spirituality: Gender Relationships and Family Patterns among Wicca and Candomblé Practitioners in Brazil

Spiritualités féministes: Relations de genre et modèles familiaux parmi les adeptes de la wicca et du candomblé au Brésil

\section{Daniela Cordovil}

\section{OpenEdition}

\section{Journals}

Edição electrónica

URL: http://journals.openedition.org/rccs/6410

DOI: $10.4000 /$ rccs. 6410

ISSN: 2182-7435

\section{Editora}

Centro de Estudos Sociais da Universidade de Coimbra

\section{Edição impressa}

Data de publição: 1 Setembro 2016

Paginação: 117-140

ISSN: 0254-1106

\section{Refêrencia eletrónica}

Daniela Cordovil, «Espiritualidades feministas: Relações de gênero e padrões de família entre adeptos da wicca e do candomblé no Brasil », Revista Crítica de Ciências Sociais [Online], 110 | 2016, colocado online no dia 26 setembro 2016, criado a 19 abril 2019. URL : http://journals.openedition.org/ rccs/6410; DOl : $10.4000 /$ rccs.6410 


\section{Espiritualidades feministas: Relações de gênero e padrões de família entre adeptos da wicca e do candomblé no Brasil}

O texto aborda um estudo comparativo entre duas religiões cujos ritos e práticas permitem a valorização da mulher e do sagrado feminino, a wicca e o candomblé. A partir de pesquisa de campo etnográfica realizada em Belém, Brasil, entre 2011 e 2015 , serão apresentados elementos da cosmovisão destas religiões que corroboram práticas feministas por parte de seus adeptos. Exploram-se as relações de gênero e os padrões de família construídos no âmbito desses dois grupos religiosos com o objetivo de mostrar como suas práticas contribuem para a valorização da mulher. Com base nesta análise etnográfica faz-se uma discussão preliminar sobre a possibilidade de analisar estes cultos a partir do conceito de espiritualidades feministas.

Palavras-chave: família; feminismo; relações de género; religião; sagrado feminino.

\section{Introdução}

A maior parte das religiões do mundo possui dogmas e posturas que tendem a corroborar o patriarcado. As representações de mundo patriarcais estão presentes em grande parte do cristianismo, do judaísmo e do islão. Tal situação de opressão feminina é tão intensa e generalizada no universo das religiões, que o pesquisador Juan José Tamayo afirma:

As religiões nunca se deram bem - e ainda hoje não se dão - com as mulheres, que são as grandes esquecidas e as grandes perdedoras. As religiões têm exercido todo tipo de violência contra as mulheres: física, psicológica, religiosa e simbólica. (2011:3)

Por outro lado, existem muitos movimentos de contestação da perspectiva patriarcal no interior das religiões. A teologia feminista tem feito diversos avanços no sentido de reconhecer a importância da mulher no cristianismo e em outras espiritualidades, antes tidas como redutos de poder masculino. 
Há também religiões cuja doutrina explicitamente reconhece o sagrado feminino e cujas práticas permitem um papel de destaque às mulheres. Este artigo irá discutir duas dessas religiões, o candomblé e a wicca, a partir de pesquisa de campo etnográfica desenvolvida entre adeptos dessa religião na cidade de Belém, no Brasil.

Os conceitos de female spirituality, espiritualidades femininas, ou Goddess worship, religiões da Deusa, vêm sendo utilizado desde os anos 1960 para caracterizar o conjunto de movimentos espiritualistas descentralizados, organizado por mulheres que cultuam diversas formas de sagrado feminino. Mulheres contemporâneas buscam reviver esses cultos inspiradas em achados arqueológicos e na obra de estudiosos que construíram uma imagem mítica de um suposto matriarcado pré-histórico (Eller, 1995; Christ, 1979).

Nestas antigas sociedades matriarcais, as mulheres seriam as grandes sacerdotisas, reverenciadas e sacralizadas pela sua capacidade de amamentar e gerar vida. As diversas estatuetas do Paleolítico chamadas Vênus, que mostram mulheres de seios e ventres fartos, foram tomadas como evidências deste suposto matriarcado pré-histórico. Este movimento está intimamente ligado aos feminismos de segunda onda, que buscavam atingir a igualdade entre os sexos, por meio da conquista de direitos como a inserção igualitária da mulher no mercado de trabalho, nos relacionamentos e na família. Uma parte importante deste movimento envolveu a busca pela reconstrução da positividade do feminino, a partir de sinais diacríticos apoiados na experiência corporal da mulher, tais como a capacidade de engravidar, menstruar e amamentar. ${ }^{1}$

Cynthia Eller (1995) chamou este culto contemporâneo do sagrado feminino, inspirado no imaginário sobre uma suposta pré-história matriarcal da humanidade, de feminist spirituality:

Um novo movimento religioso iniciado nos anos 1970 que nos dias de hoje está crescendo e florescendo nos Estados Unidos e Canadá, em partes da Europa continental e Inglaterra, e até na Austrália. Ele é um movimento popular espontâneo, sem nenhuma organização global, nenhum sistema de liderança e nenhuma forma regularizada de adesão. Inspira-se em muitas tradições religiosas, mas não responde a nenhuma. Não possui institucionalização nem estruturas rígidas, e está em constante fluxo. (1995: 3)

Segundo Cynthia Eller, não é possível determinar onde começa e onde termina o movimento das espiritualidades feministas e quem são aquelas que

\footnotetext{
${ }^{1}$ Por este motivo tais movimentos foram criticados pelo feminismo de terceira onda, que rejeita estas associações naturalizantes entre o feminino e o corpo da mulher (Braidotti, 2001).
} 
dele participam. Em seu estudo Living in the Lap of the Goddess, a autora utilizou como critério para definir quem são as feministas espiritualistas a autoidentificação. Ou seja, praticam espiritualidades feministas aquelas que se identificam como tal. Além deste critério, a autora aponta quatro características presentes nas espiritualidades feministas:

1) o movimento é separatista, centrado na mulher;

2) o movimento está fora das religiões tradicionais como o cristianismo e o judaísmo e faz parte do grupo das religiões alternativas;

3) o movimento é feminista e suas líderes se percebem como tal;

4) as espiritualidades feministas são centradas no mundo anglófono, especialmente nos Estados Unidos e Canadá (ibidem: 7-8).

O estudo de Cynthia Eller constitui uma brilhante amostra e caracterização do modo como as espiritualidades feministas se estruturam em um contexto específico de encontro entre o ideário feminista e as novas espiritualidades dos anos 1970. As espiritualidades feministas estudadas por Eller são praticadas por mulheres predominantemente brancas, que cultuam em sua maioria deusas oriundas de um contexto cultural Europeu. A mesma autora demonstra que a incorporação do culto às Deusas negras pelas espiritualidades feministas pode tornar-se uma estratégia problemática e inconsciente, utilizada pelas mulheres brancas que compõem este movimento, para esquivar-se da culpa do racismo (Eller, 2000).

Nesta pesquisa, proponho pensar as espiritualidades feministas para além do grupo social e do contexto histórico originalmente estudado por Eller. As religiões afro-brasileiras e neopagãs que estudei no Brasil reconhecem a divindade com características femininas, cultuam deusas e permitem à mulher o exercício do sacerdócio. Estas religiões possuem discursos e práticas de sacralização da mulher e do feminino que possibilitam aos seus adeptos engajarem-se em movimentos sociais ou em práticas de cunho feminista, gerando transformações em sua vida privada e na sociedade.

Para buscar caracterizar o feminismo no candomblé e na wicca explorarei dois aspectos dessas religiões: as relações entre os gêneros e os padrões de família. No aspecto das relações entre os gêneros irei mostrar como em ambas as religiões existe grande possibilidade de mulheres atingirem papéis de liderança, apesar de este espaço também poder ser ocupado por homens.

No que diz respeito aos padrões de família, apresentarei os diversos modelos desejados e praticados dentro das religiões, esclarecendo como as famílias e os relacionamentos facultados pela cosmovisão religiosa vão além do modelo de família patriarcal e monogâmica. Os padrões de vida construídos com auxílio de práticas religiosas contribuem para o engajamento 
de seus adeptos em discussões contemporâneas sobre família e relações de gênero no espaço público, aspecto que também será explorado neste artigo.

O texto está estruturado nas seguintes partes: nas duas primeiras, irei analisar brevemente os fundamentos históricos e teológicos da wicca e do candomblé; em seguida, apresentarei como se dão as relações entre os gêneros em ambas as religiões, e depois falarei dos modelos de família consagrados por elas; irei, por fim, destacar como se dá a prática e a militância feminista por parte dos adeptos dessas religiões nos grupos estudados por mim em Belém, no Brasil.

A pesquisa foi desenvolvida através de uma combinação de pesquisa de campo e bibliográfica. O levantamento de dados empíricos baseou-se nos fundamentos da etnografia e da observação participante. A pesquisa de campo etnográfica compreende uma imersão na cultura e nas vivências do grupo pesquisado com objetivo de apreender o mundo a partir das categorias do grupo, produzindo interpretações a partir das interpretações dos nativos, ou "descrições densas" (Geertz, 1978).

A pesquisa de campo teve lugar nas cidades de Belém, São Paulo e Brasília, entre 2011 e 2015. Os dados coletados no Brasil sobre religiões afro-brasileiras foram levantados no período entre 2011 e 2013. Neste período estive envolvida com a pesquisa "Religião e política entre afrorreligiosos na Amazônia" realizada em Belém, Pará. Este estudo tinha como foco a análise da forma como as religiões afro-brasileiras deixaram de ser religiões perseguidas pelo Estado e marginalizadas pela sociedade para se tornarem um grupo religioso politicamente reconhecido e atuante no Brasil contemporâneo (Cordovil, 2014).

Durante a pesquisa foi feito um levantamento de associações civis comandadas por afrorreligiosos na cidade de Belém e foi realizada uma entrevista com suas principais lideranças, assim como o acompanhamento de eventos políticos, caminhadas, palestras, etc. Foram também realizadas entrevistas com sete lideranças, três homens e quatro mulheres. Consultaram-se ainda fontes secundárias em jornais e na internet. A pesquisa corroborou um dado já apontado por pesquisadores que se debruçaram sobre as religiões afro-brasileiras - a existência de uma grande quantidade de mulheres como sacerdotisas e líderes do culto, o que não exclui a liderança masculina (Landes, 2002; Matory, 2005).

A escolha das lideranças que participaram na pesquisa foi feita de acordo com o seu grau de engajamento político e com a promoção de políticas públicas. Ou seja, foram escolhidos propositadamente para participar do estudo apenas os sacerdotes e sacerdotisas que possuíam engajamento direto ou indireto com a promoção dessas políticas. 
Os dados deste trabalho e a posterior observação de um fenômeno semelhante na wicca inspiraram a proposta e elaboração de uma pesquisa que comparasse os motivos da adesão e preponderância feminina nas duas religiões.

A pesquisa sobre praticantes de wicca teve início em 2013, a partir da observação participante realizada em rituais e eventos públicos desta religião promovidos pela Abrawicca - Associação Brasileira de Arte e Filosofia da Wicca - em Belém, Pará. A partir dessa observação e do contato com esses grupos, passei a frequentar os eventos nacionais promovidos por esta associação em São Paulo e Brasília, entre 2014 e 2015. Entre as atividades acompanhadas estava o Círculo de Mulheres, restrito a participantes do sexo feminino (Cordovil, 2015). Foram realizadas entrevistas com sete praticantes da religião, cinco mulheres e dois homens.

De forma semelhante ao que foi feito com relação ao candomblé, procurei entrevistar e me envolver com grupos e pessoas que possuem uma militância ou liderança pública nesta religião. O critério para estabelecer a relevância destes grupos foi etnográfico, já que era possível observar os seus rituais e eventos sendo realizados em espaços públicos e centros holísticos da cidade de Belém. Também realizei a pesquisa na internet, onde se pode facilmente encontrar indícios da presença dessas lideranças na mídia, em websites e em diversos estudos acadêmicos.

Assim como no caso do candomblé, a pesquisa sobre wicca partiu da análise de uma realidade local, os grupos que praticam estas religiões na cidade de Belém. A possibilidade de frequentar eventos nacionais, no caso da wicca, e de observar as articulações nacionais dos afrorreligiosos, assim como a pesquisa em documentos e fontes da internet, permite realizar algumas generalizações a respeito do contexto e da militância destes grupos religiosos em um cenário nacional. No entanto, essas generalizações devem ser feitas de maneira limitada e cautelosa, em se tratando de um país como o Brasil, que possui dimensões continentais, impossíveis de serem abrangidas por uma única pesquisa empírica.

Porém, como afirma Clifford Geertz (1978), os antropólogos pesquisam em aldeias, o que significa que as questões universais só podem ser resolvidas dentro da tradição antropológica a partir de uma observação local, sujeita aos condicionamentos e "imponderáveis" da pesquisa.

\section{Candomblé}

O candomblé é uma religião afro-brasileira surgida na Bahia do século XIX a partir de contribuições culturais de ex-escravos de descendência iorubana, que fundaram os primeiros "terreiros" ou templos dessa religião 
em Salvador. Além do candomblé, o Brasil possui dezenas de religiões afro-brasileiras que variam de acordo com a região do país e a cultura dos grupos étnicos africanos que serviram de base à sua liturgia. Algumas das mais conhecidas são a umbanda, o batuque, o xangô, o catimbó e o tambor de mina ou mina-nagô.

As religiões afro-brasileiras foram consideradas por diversos estudiosos como espaços de resistência da cultura africana no Brasil (Rodrigues, 2004; Bastide, 2001). O grau desta resistência variou de acordo com o sincretismo admitido no culto. Enquanto algumas das religiões afro-brasileiras se tornaram mais próximas das religiões cristãs, outras optaram por manter as tradições africanas ou reconstruí-las.

Dentre as religiões consideradas pelos seus adeptos mais tradicionais ou menos sincréticas está o candomblé. Seus princípios doutrinários e litúrgicos são o resultado de negociações entre as elites fundadoras do culto, provenientes da África e as adaptações realizadas no Brasil (Matory, 2005), o que denota a existência de mudança e sincretismos na construção desta religião. No entanto, entre os afrorreligiosos no Brasil, é corrente a crença de que o candomblé seria a religião de matriz africana que mais se aproxima dos cultos praticados na África, por admitir formalmente menor grau de mudança nos cultos. Desta forma, as noções do que é tradicional ou sincrético estão sendo utilizadas aqui a partir de categorias nativas e não analíticas.

A liturgia do candomblé baseia-se no culto a dezesseis orixás, divindades africanas iorubanas, que incorporam nos fiéis por meio do transe e também respondem a consultas através do oráculo do jogo de búzios. Por meio dos búzios é possível conhecer a vontade dos orixás e buscar satisfazê-la com oferendas e sacrifícios, de forma a conseguir que eles intervenham em prol da felicidade humana (Augrás, 2008).

Um aspecto que chamou atenção de pesquisadores das religiões afro-brasileiras foi a grande presença de mulheres como lideranças dos cultos. Os estudos de Nunes Pereira (1979) e Sérgio Ferretti (2009) realizados na Casa das Minas, tradicional templo religioso do Tambor de Mina, religião afro-brasileira presente em São Luís, no Maranhão, demonstraram que todas as lideranças do culto eram mulheres, não sendo permitido aos homens submeter-se ao processo iniciático que torna o adepto preparado para receber as divindades em estado de transe.

Na década de 1930, a antropóloga norte-americana Ruth Landes realizou pesquisa de campo em Salvador e com base nesta pesquisa publicou um polémico artigo onde afirma a existência de um matriarcado nos terreiros de candomblé nagô em Salvador, por serem em grande parte liderados 
por mulheres, que possuem total autonomia na administração dos templos (Landes, 1940). A autora também observou o surgimento de uma outra vertente de culto, os candomblés de caboclos, onde os homens podiam entrar em transe com as divindades e assumir a liderança dos cultos. Esses homens sacerdotes possuíam comportamentos homossexuais. Para a autora, a religião foi o espaço encontrado por esses homens onde sua orientação sexual poderia ser bem aceita:

As fantasias dos homossexuais passivos são concretizáveis sob a proteção do culto, como os homens dançarem com mulheres desempenhando papéis das mulheres, usando saias e agindo como médiuns. Um dos mais notáveis atributos dos "pais" em destaque é o seu estilo de dança nos rituais. Ele é estereotipadamente feminino, especialmente na sua forma de ser lento e sensual (dengoso), e é marcadamente diferente das formas atléticas cultivadas pelos homens nas danças seculares. (ibidem: 394)

Apesar de duramente criticada por seus pares na época, a tese de Landes se mostrou correta, pois é comprovada a possibilidade de mulheres e homossexuais masculinos assumirem a liderança de templos religiosos afro-brasileiros, onde possuem grande prestígio. Nas palavras de Mãe Stella de Oxóssi, líder de um dos mais antigos e tradicionais terreiros de candomblé de Salvador, o Ilê Axé Opô Afonjá:

A liderança feminina no candomblé é uma coisa muito forte, porque a mãe é mulher. Por mais rude ou enérgica que ela seja, sempre tem aquela nuance feminina para determinados detalhes. [...] O homem tem o valor dele, existem pais-de-santo competentes, verdadeiros. Podemos dizer que o candomblé, na atualidade, não é uma crença, uma religião só de negros, nem só de mulheres. (Oxóssi, 2015)

Segundo Patrícia Birman (1995), em pesquisa realizada entre membros da umbanda e do candomblé no Rio de Janeiro, o estado de transe com a divindade é considerado na cosmovisão das religiões afro-brasileiras como simbolicamente feminino, o que torna a mulher mais apropriada do que o homem para esta função. Como tradicionalmente apenas pessoas que entram em transe podem assumir a liderança das casas de culto, geralmente veremos mais lideranças femininas na religião. Também por o aspecto do transe ser considerado feminino, os homens que entram em transe geralmente são percebidos como homossexuais e a grande maioria deles de fato possui esta orientação sexual. O termo adé é utilizado pelos candomblecistas para referir-se a estes homens com comportamento feminino: 
Os adés, ao contrário dos filhos-de-santo comuns, "adoram" o transe e a todo o momento fazem questão de praticá-lo. Por isso têm, nos candomblés, uma atividade em parte sujeita a censuras: o falso transe, denominado dar ekê. Os adés adoram dar ekê. Especialistas em possessão, eles fazem dessa habilidade algo que arrepia os bastiões de moralidade no candomblé, como mestres que são em apresentar falsas possessões. Dar ekê significa uma exibição paroxística de competência nesse domínio obscuramente sexualizado e feminino. (Birman, 1991: 51-52)

Entre os homens que entram em transe, o comportamento de exibir propositadamente trejeitos e maneirismos femininos caracteriza um indivíduo adé, ou bicha, termo utilizado em linguagem coloquial no Brasil para designar um homem homossexual com comportamento feminino.

Dentro da tradicional divisão de trabalho dos terreiros, os homens heterossexuais costumam assumir o cargo de ogã, que é a pessoa responsável pelos sacrifícios de animais e pelo toque de instrumentos musicais nos rituais. No passado, esses ogãs podiam se tornar também protetores das religiões, advogando por elas no espaço público. Como afirma Landes:

A estrutura do culto requer homens como ogãs, "provedores”, "protetores”. Espera-se de um ogã que pague pelas elaboradas cerimônias, que execute reparos na casa de culto, e que auxilie financeiramente pelo menos uma das sacerdotisas nas suas obrigações rituais. Às vezes, o ogã é obrigado a defender o culto diante da polícia. (1940: 390-391)

$\mathrm{Na}$ divisão de trabalho nos terreiros, as mulheres são as grandes líderes, porém essa liderança se exerce mais no aspecto privado, onde gerenciam todos os cuidados de organização da casa e interferem plenamente na vida dos filhos e filhas de santo, os iniciados na religião. Birman reitera esta relação entre as mulheres e o aspecto feminino com o lado mais privado do culto:

A organização dos terreiros enquanto núcleos domésticos tem na "reprodução", ou seja, no cultivo cuidadoso da relação com os orixás, que inclui permanentemente o fazer novos filhos-de-santo, a sua razão fundamental de existência. Para a existência do núcleo doméstico, portanto, o que deve prevalecer em termos das relações de gênero é a presença de mulheres concernidas à sua esfera doméstica. Os homens, voltados para a esfera pública, exterior, são elemento de apoio à reprodução desse núcleo. (Birman, 1991: 54)

No aspecto cosmológico, os orixás cultuados no candomblé podem ser femininos, masculinos ou metás (possuem os dois gêneros). Ao passar 
por um processo iniciático, uma pessoa que adentra a religião é consagrada para um desses orixás, considerado o regente de sua cabeça, ou ori. O orixá poderá influenciar a sexualidade e a performance de gênero do adepto. Considera-se que pessoas regidas por orixás femininos tendem a ter a personalidade mais feminina; se forem mulheres, será provável que sejam heterossexuais. No caso dos homens, o orixá pode influenciar bastante a sexualidade e a performance de gênero do adepto; pois geralmente homens homossexuais que possuem um comportamento feminino possuem orixás femininos.

No universo dos terreiros de candomblé são diversos os momentos em que o sagrado feminino é valorizado. Essa valorização se dá pelo culto aos orixás femininos e metás, a reprodução de seus mitos e suas liturgias e pelo papel de liderança exercido pelas mulheres e homossexuais masculinos afeminados nos templos religiosos.

Como é possível supor, a experiência de resistência cultural e de liderança feminina fortemente presente nos terreiros os qualifica a engajarem-se em lutas feministas, tanto no espaço público quanto na esfera privada do terreiro. Atualmente no cenário das lutas políticas e sociais desenvolvidas no Brasil por esses religiosos existe um número expressivo de mulheres sacerdotisas da religião, como será discutido mais adiante.

\section{Wicca}

A wicca é uma religião neopagã surgida na Inglaterra na década de 1950, que tem como marco de fundação a publicação da obra do funcionário público aposentado Gerald Gardner (Hutton, 1995). Em seus livros, Gardner descreve uma religião baseada no culto da natureza, entendida como sagrada. A ritualística da religião baseia-se na celebração de oito festivais sazonais, chamados Sabaths, que estão ligados às mudanças de estações do ano. Estes festivais relacionam-se com o ciclo de nascimento e morte do Deus, ou princípio sagrado masculino. O poder feminino na religião é celebrado pela alternância das fases da Lua, consideradas manifestações da deusa. Estes rituais lunares são chamados Esbaths. Os rituais da wicca celebram simbolicamente a união sexual entre o deus e a deusa, considerado um ato sagrado e gerador de tudo o que existe na natureza (Adler, 2006).

A wicca é uma das vertentes do neopaganismo, conjunto de religiões baseadas no culto da natureza e na recriação de práticas ritualísticas de povos antigos ou pré-cristãos. Nas décadas seguintes à sua criação, a nova religião espalhou-se pela Europa e pelos Estados Unidos, influenciando militantes da contracultura e da segunda onda do feminismo (Pike, 2004). 
As pessoas que criaram e recriaram o Paganismo em meados do século XX estavam amplamente motivadas por objetivos religiosos, e olharam para o passado para modelos de práticas religiosas animistas, politeístas e xamânicas. O impulso inicial foi conscientemente em relação às religiões e os textos do período clássico e da Europa pré-cristã que foram trabalhados como religiosos. Mais tarde, os pagãos foram influenciados pelo feminismo de segunda onda e pelo crescente movimento ambiental. (Chifton e Harvey, 2004: 1)

$\mathrm{Na}$ Califórnia dos anos 60, a Wicca Reclaiming, fundada por Starhawk, reuniu um grupo de mulheres e homens engajados com o movimento anarquista, feminista e LGBT. Na obra The Enchanted Feminism, Jone Salomonsen faz um relato etnográfico sobre como se organizaram os primeiros grupos Reclaiming na Califórnia dos anos 1970 e 80, em conexão com vários movimentos contraculturais ocorridos no período (Salomonsen, 2002). Além da vertente Reclaiming, existe também a Wicca Diânica, criada por Zsusana Budapest, que não admite a iniciação de homens e baseia toda a sua liturgia na celebração do poder e dos mistérios femininos, como a gravidez e a menstruação.

A wicca chega ao Brasil na década de 1980, encontrando adeptos entre pessoas ligadas aos movimentos e espiritualidades Nova Era, muito populares neste período (Bezerra, 2012). A partir dos anos 1990 e 2000 a wicca brasileira cristaliza-se em grupos fechados (chamados de tradições) e surgem as primeiras lideranças em busca de legitimidade e reconhecimento público. Neste período foram fundadas algumas associações civis como a Abrawicca, com o objetivo de dar visibilidade à nova religião. Atualmente, a wicca no Brasil conta com diversas associações civis estruturadas e uma forte militância pública no campo do reconhecimento da diversidade religiosa (Terzetti Filho, 2014).

As questões de gênero são permanentemente discutidas pelos praticantes da Wicca. Toda a cosmovisão wiccaniana baseia-se na desconstrução do patriarcado, considerado um grande empecilho à felicidade humana. Para o praticante da wicca, o objetivo da religião é trazer felicidade e plenitude aos seres humanos na sua vida na Terra. Não faz sentido para os wiccanianos a ideia de punição, castigo ou culpa, pois não acreditam em um outro mundo mais pleno e perfeito, como ocorre no cristianismo; buscam a felicidade na sua existência atual.

Os wiccanianos consideram que o reconhecimento do prazer sexual e sua vivência plena são necessários para atingir a felicidade e também para sua conexão com a espiritualidade. Como muitos foram educados dentro do cristianismo, buscam libertar-se da cosmovisão cristã, a fim de atingirem 
o que propõe a wicca. Para atingir esse desprendimento, realizam uma série de estudos e vivências que tem como objetivo gerar a reflexão em torno da sexualidade e dos papéis de gênero. Essa reflexão faz parte de um processo denominado por eles de autoconhecimento, fundamental para sua prática religiosa. Acreditam que por meio deste autoconhecimento e reflexão sobre traumas do aprendizado social é possível libertar-se das amarras do patriarcado, alcançando uma existência mais plena e feliz.

Para a wicca a natureza é sagrada e o acesso a este sagrado se dá de forma imanente, ou seja, não existem mediações. A natureza é a própria Deusa e tudo que existe nela é sagrado, inclusive o ser humano considerado parte da Deusa.

Além da wicca, existem outras vertentes de paganismo cuja ênfase é o culto ao sagrado feminino. Chamadas de Goddess spiritualities, essas religiões não possuem estrutura ritual fechada como a wicca, e a relação entre feminismo, religião e ecologia costuma ser fortemente trabalhada:

O compromisso político dessas mulheres com as filosofias ambientais e sua visão de mundo, que percebe a humanidade entrelaçada em uma rede de relações sagradas com o resto da natureza, é vivido como uma experiência diária. As espiritualidades da deusa podem não possuir uma doutrina elaborada com a qual todas as participantes são solicitadas a concordar, mas existem muitas evidências que sugerem que muitas "walk the talk" de suas crenças pessoais sobre a natureza. A prática ritual e as experiências vividas, mais do que uma doutrina, formam o coração da comunidade. Muitas vezes existe uma linha contínua entre prática ecológica e rituais espirituais. (Rountree, 2005: 148)

$\mathrm{Na}$ wicca e em outros grupos pagãos, o sagrado feminino é considerado a experiência de reconhecer a deusa em tudo na natureza. Entre os wiccaniamos encontramos um elaborado discurso de valorização da mulher, mesmo entre os homens. Um jovem praticante da religião, entrevistado em Belém, fala sobre a sua experiência de cultuar o sagrado feminino:

Tenho muitos vasos, tenho muitas plantas em casa, e a partir disso, eu comecei a ver como eu vou fertilizar aquilo ali, como que eu vou fertilizar a minha relação com a minha mãe, com a minha avó, com a mulher que eu encontrar no ônibus, com a minha namorada, como é que eu vou fertilizar isso, como é que eu vou ver, enxergar, o útero de uma forma a não ferir mais, porque ele já vem de um processo de cura, eu não posso interromper isso, entende?2

${ }^{2}$ Entrevista concedida em 23.03.2015. 
Nesta fala, o praticante, um jovem de 20 anos, demonstra que desenvolver uma relação respeitosa com as mulheres é parte fundamental da sua maneira de compreender sua vivência religiosa. O sagrado feminino, para ele, está também em tratar bem as mulheres com as quais se relaciona. Considera esse aspecto da sua vida sagrado, uma forma de se relacionar com a Deusa. A fala do praticante mostra o aspecto da imanência, ou seja, reconhecer o sagrado no mundo fenomênico, na sua relação com as pessoas e com a natureza.

\section{Relações de gênero}

Como vimos, tanto a wicca quanto o candomblé possuem uma cosmologia onde o papel da mulher é muito destacado, o que as coloca como sacerdotisas ou líderes natas destas religiões. Como era de se esperar, essas cosmovisões geram padrões de relações entre os gêneros bastante específicos.

No caso do candomblé, os papéis femininos e masculinos são rigidamente codificados dentro do universo do terreiro. Segundo os critérios de classificação nativa, há apenas dois tipos de pessoas em um terreiro de candomblé, os rodantes e os não rodantes. Os primeiros possuem capacidade de entrar em transe, os segundos não. Combinando esse aspecto com a dicotomia sexual, esses papéis passam a ser quatro: mulheres rodantes, homens rodantes, mulheres não rodantes, homens não rodantes. Não existe grande distinção entre as atribuições litúrgicas dos rodantes, sejam eles homens ou mulheres. Compete-lhes entrar em transe com as divindades nos momentos litúrgicos, consultar o oráculo, realizar oferendas votivas e ocupar-se de diversos aspectos da organização física do terreiro. Ambos podem chegar à liderança do terreiro (Birman, 1995).

No caso dos não rodantes existe grande diferença de atribuições em se tratando de mulheres ou de homens. As mulheres ocupam o cargo de ekédis, que são assistentes dos fiéis que entram em transe, cuidam de suas roupas e paramentos litúrgicos, da preparação das comidas votivas e também da organização do tempo. Por outro lado, os homens não rodantes ocupam o cargo de ogãs, suas atribuições litúrgicas dizem respeito à imolação de animais votivos e à precursão de instrumentos musicais durante o ritual.

Por esta divisão de trabalho entre os gêneros, podemos perceber que as mulheres ocupam muitos papéis simbolicamente relacionados à cozinha, ao espaço doméstico, ao cuidado e à nutrição. Por outro lado, mesmo sendo o terreiro um lugar público, existem níveis onde ele permite a exposição a estranhos. As festas públicas são o principal momento onde se recebe os de fora. Nessas festas, os ogãs ocupam papel importante, pois são responsáveis pela música ritual. 
Na militância política construída atualmente pelos afrorreligiosos, existem muitos ogãs envolvidos com políticas públicas. Eles acabam sendo uma espécie de relações públicas do terreiro, em situações onde a sacerdotisa não possui tanta desenvoltura para lidar com políticos e gestores. No entanto, mesmo sendo os ogãs os maiores mediadores da relação do terreiro com o público, as mulheres, especialmente as sacerdotisas, têm vindo a ocupar um papel de destaque nesse diálogo (Cordovil, 2013). Em todo o caso, a relação entre homens e mulheres precisa ser sempre de respeito e hierarquia e nos terreiros chefiados por mulheres elas são bastante veneradas.

Ouro aspecto importante da distinção rodante $v$ s. não rodante, diz respeito à sexualidade. Geralmente os homens que são ogãs, não rodantes, possuem orientação heterossexual, constituindo simbolicamente o grupo mais próximo do aspecto masculino do terreiro (Fry, 1982). Os homens homossexuais são mais encontrados enquanto rodantes e as mulheres homossexuais podem ser encontradas tanto entre as rodantes quanto entre as ekédis. Existe assim uma grande variação de papéis de gênero e orientações sexuais possíveis no terreiro e a cosmologia da religião reflete isso (Birman, 1995).

O candomblé é uma religião de tradição oral, que se manteve no Brasil desde o século XIX a partir de grandes processos de reinvenção cultural. Existe consulta a textos escritos na religião e muitos sacerdotes produzem obras escritas, recorrendo também fortemente ao trabalho de pesquisadores, no entanto, o cerne dos conhecimentos relativos à religião ainda é transmitido oralmente. Saberes a respeito da cozinha litúrgica, da composição das oferendas votivas, da consulta ao oráculo, dos mitos relativos aos orixás, tudo isso é transmitido por via oral. As preocupações referentes à obtenção e manutenção destes saberes ocupam grande parte do cotidiano e da vida litúrgica de um terreiro. O debate a respeito da natureza do homem e da mulher e dos papéis de gênero é algo mais vivido e sentido do que objeto de uma produção discursiva própria.

$\mathrm{Na}$ wicca, por outro lado, o debate a respeito do papel do homem e da mulher na religião ocorre de forma racionalizada. Os adeptos da wicca, na sua maioria, conheceram a religião a partir do envolvimento com movimentos e espiritualidades Nova Era, são pessoas de estratos sociais médio e alto, valorizam muito o hábito da leitura e da internet (Bezerra, 2012; Guerriero, 2006). Por esse motivo, e por se tratar de uma religião de codificação bastante recente, a maioria das atividades e da ritualística da wicca é oriunda de uma reflexão racional e deliberada sobre papéis de gênero e relações entre homens e mulheres.

A wicca é considerada pelos seus adeptos uma religião sacerdotal e iniciática. Isso significa que não existem fiéis, todos os que praticam a wicca 
são sacerdotes e devem aprender a conduzir seus próprios rituais. Por isso, a religião não possui a diferenciação de papéis litúrgicos que se encontra no candomblé. Por outro lado, os ritos sacerdotais em honra aos deuses pagãos variam conforme o gênero do praticante. Tanto os homens quanto as mulheres devem cultuar o sagrado feminino e o sagrado masculino, mas, obviamente, o culto é diferenciado segundo o gênero do praticante. Cada praticante deve eleger, dentre os deuses pagãos, um panteão que será objeto de seu culto particular. Normalmente, homens terão predominância de culto a deuses masculinos e mulheres cultuarão com mais ênfase divindades femininas. Isso não ocorre de forma excludente, pois os pagãos consideram que o sagrado feminino e masculino está tanto em homens quanto em mulheres.

Existem também momentos ritualísticos específicos para homens e mulheres nas práticas da religião, os Círculos de Mulheres e os Círculos de Homens, onde se celebram os mistérios do sagrado masculino e do sagrado feminino. Esses chamados mistérios estão relacionados a processos naturais e fisiológicos de cada gênero, considerados sagrados. Assim, nos Círculos de Mulheres discutem-se aspectos relacionados à menstruação, à gravidez e à maternidade, consideradas partes da sacralidade do feminino (Cordovil, 2015). Na fala da sacerdotisa wiccaniana Danna Myr, de 49 anos:

O sagrado feminino eu percebo naquilo que me caracteriza como mulher, que são as coisas mais essenciais, as coisas mais naturais que fazem me sentir como mulher. Por exemplo, é a relação com o sangue, o sangue pra mim é aquilo que me identifica como mulher. A maternidade, a amamentação, tudo isso é o sagrado feminino pra mim, é sagrado, porque dentro de todo esse, essa natureza, esse mecanismo todo de menstruar, de ovular, de engravidar, de amamentar, de alimentar uma outra vida que povoa o mundo, que povoa todo o universo, que transforma o universo, pra mim esse é o sagrado feminino, é assim que eu percebo. ${ }^{3}$

Podemos perceber que na wicca a espiritualidade está ligada fisicamente à condição de ser homem ou ser mulher e aos processos fisiológicos que surgem de aspectos inerentes a cada gênero. Por outro lado, em termos de liderança e funções sacerdotais elas são bastante semelhantes para ambos os gêneros, já que na religião todos se consideram sacerdotes.

\section{Padrões de família}

Segundo seus costumes e a visão de mundo religiosa, tanto o candomblé quanto a wicca reconhecem e aceitam padrões de família não tradicional,

\footnotetext{
${ }^{3}$ Entrevista concedida em 14.03.2015.
} 
ou seja, famílias que não se adequam ao modelo de casamento entre um homem e uma mulher e uma descendência formada pelos filhos consanguíneos deste casal. Porém, isso se dá de forma diferente em cada uma dessas religiões.

No candomblé, por se tratar de uma religião de diáspora africana, a família nuclear foi abalada durante o processo de escravidão, surgindo como padrão preponderante as famílias monoparentais lideradas por mulheres.

Nesses espaços, prevalece o tipo de mulher que é responsável pelo sustento da família. Ali há muita rotatividade entre casais e o homem não assume o papel de responsável pela sobrevivência da família, cabendo à mulher essa função. Conhecemos vários exemplos de famílias chefiadas por mulheres, principalmente nas classes mais carentes. Percebemos assim, uma redefinição das identidades de gênero, uma redefinição do que se espera que homens e mulheres façam socialmente. (Bastos, 2009: 163)

Também por conta da diáspora, a adoção foi e ainda é um aspecto fortemente valorizado entre afrorreligiosos, que tendem a identificar-se mais fortemente com a família litúrgica do que com a família consanguínea (Segato, 2005). É comum encontrar entre adeptos de religiões afro-brasileiras uma grande tolerância quanto a arranjos familiares homoafetivos e à presença de filhos adotivos. Em muitos casos esses arranjos chegam a ser os mais desejados.

Isso ocorre de maneira tradicional na religião, não constitui foco de militância ou discurso, mas sim de práticas. Não existe no candomblé uma discussão a respeito de comportamentos considerados bons, apropriados ou desejáveis. Isto não significa que não existam normas, nem princípios éticos nos terreiros. Porém, esta ética é toda direcionada para a relação fiel-orixá, ela pouco ou nada fala sobre a relação entre os fiéis entre si ou dos fiéis com outras pessoas que não praticam a religião.

Não faz diferença nenhuma em termos litúrgicos qual a orientação sexual ou estrutura de família vivenciada pelo fiel, pois é algo que não diz respeito à sua vida religiosa. Para adeptos do candomblé, o que importa é atingir a felicidade e uma vida plena, não se debatendo o modo como isso preferencialmente deveria ser feito. Essa cosmovisão repercute no surgimento de modelos de família, de casamento e de sexualidade diferentes daqueles praticados por adeptos de outras religiões. Neste sentido, o candomblé é semelhante à wicca e a outras religiões pautadas pela imanência; como não existe uma aspiração a outro mundo considerado mais perfeito e desejável, há maior tolerância a diversos modos de vida. 
Já na wicca, existe uma forte militância com relação ao casamento homoafetivo e ao reconhecimento de direitos de famílias não convencionais. Alguns adeptos da wicca vivem ou buscam viver relações poliamorosas. É parte importante da visão de mundo da wicca a vivência plena e saudável da sexualidade. Como na wicca, a percepção religiosa de mundo permite e encoraja vivências sexuais e afetivas isentas de culpa, os adeptos desta religião procuram preferencialmente parceiros que compartilhem de sua visão de mundo. $\mathrm{Na}$ fala do jovem Elros, de 20 anos, cuja namorada também pratica a wicca:

Pra nós uma terceira pessoa dentro de um relacionamento é uma coisa muito complicada... "que religião é a dela?”. Existe uma necessidade de que seja algo próximo, compreensivo, porque se não for... armados nós estamos, mas vamos estar nos abrindo pra isso, se tornando vulneráveis, e vulneráveis de uma forma, assim... muito vulnerável, por ser um relacionamento amoroso, e as pessoas fazem loucuras por amor, e pra um bruxo isso é muito cauteloso, não só por causa das doenças sexualmente transmissíveis, ou por causa das desconfianças, mas também por causa da vida sacerdotal. ${ }^{4}$

A fala do informante mostra um pouco da visão de mundo da religião acerca de família e da sexualidade. É uma cosmovisão que valoriza a fruição e o prazer, as relações amorosas entre as pessoas independentemente de qualquer padrão preestabelecido, sendo por isso tolerante com as relações homoafetivas e arranjos poliamorosos. Muitos jovens que adentram a wicca o fazem, entre outros aspectos, por uma idealização de um universo religioso de liberdade e valorização positiva da sexualidade. Entre este grupo há aqueles que buscam o poliamor como um ideal de relacionamento. Na fala de uma conceituada sacerdotisa da religião que vive há cinco anos com dois maridos, esses jovens são wannabes, ou seja, o poliamor para eles representa um desejo e um ideal de vida, não se trata de uma prática real.

Apesar de existirem alguns pagãos que são poliamorosos e outros que desejam este modo de vida, ele não pode ser considerado a regra, nem no meio pagão. Assim como em outros ambientes, no paganismo predominam os relacionamentos duais, que podem ser homo- ou heterossexuais, monogâmicos ou relações abertas.

Em linhas gerais, a questão da sexualidade e dos relacionamentos ocupa grande espaço nas discussões e na cosmologia wiccaniana. O Encontro Anual de Bruxos, realizado em São Paulo, em março de 2015, teve como tema a sexualidade sagrada. Todos os rituais realizados no evento aconteceram

\footnotetext{
${ }^{4}$ Entrevista concedida em 23.03.2015.
} 
em honra da deusa Turan, uma deusa etrusca ligada ao amor, à beleza e à prostituição sagrada. Houve diversos workshops e debates envolvendo a temática da sexualidade, sob os mais diversos aspectos, e a questão do poliamor foi tema de uma palestra.

O ritual religioso de casamento na wicca chama-se handfasting, sendo que por meio deste ritual os noivos celebram sua união em um compromisso diante dos deuses. Não existe uma quantidade ou padrão preestabelecido sobre quem deve tomar parte no ritual, que pode teoricamente acontecer entre casais hetero- ou homossexuais ou entre mais de duas pessoas. Como consideram que a base do casamento é o consenso, o ritual deve ser renovado anualmente.

Por outro lado, no candomblé a sexualidade e a família não ocupam um espaço privilegiado nas discussões. Os adeptos dessa religião vivenciam modelos de famílias não monogâmicas em seu cotidiano. É muito comum que as lideranças de terreiros, principalmente os homens, sejam homossexuais. Seus parceiros amorosos geralmente vivem nos templos e assumem funções litúrgicas. Se um homem homossexual é líder de um terreiro e possui um companheiro, este pode ocupar um espaço na religião, provavelmente como um ogã. Muitas vezes, quando se divorciam, os ex-companheiros podem continuar próximos ao sacerdote, habitando sua casa como agregados. Existem casos em que esses homens se casam com mulheres, que passam também a integrar o núcleo familiar; seus filhos são considerados pelo sacerdote como netos.

Não existe um modelo de ritual de casamento no candomblé. Ele pode ser realizado, mas não é comum. São mais frequentes entre adeptos do candomblé as uniões consensuais, o que é considerado pelos pesquisadores uma herança do modelo de família estabelecido pela diáspora (Landes, 2002).

A família de santo é um modelo de parentesco fictício surgido no período colonial da necessidade de os escravos refazerem os laços desfeitos pela escravidão. No terreiro, espiritualmente todos são parentes entre si, a mãe de santo ou pai de santo e seus filhos constituem uma família extensa no sentido moral e prático, pois possuem deveres de ajuda mútua e muitas vezes coabitam no mesmo espaço.

A bissexualidade masculina e feminina está bastante presente nos terreiros de candomblé (Segato, 2005). Na wicca, apesar de esta ser uma orientação sexual frequente, a muitos adeptos não agrada este termo, assim como não se sentem confortáveis com os rótulos de homo- e heterossexual, pois consideram que a sexualidade consiste em uma possibilidade de fruição de prazer que não deve ser enquadrada em categorias preestabelecidas. 


\section{Feminismos, debates e militâncias}

Entre o povo do santo, em geral, aqueles que se engajam com movimentos políticos e sociais correspondem a uma pequena parcela da população que frequenta terreiros. Para se ter uma ideia, um senso realizado pelo governo federal em 2011 (Brasil, 2011) identificou 1048 terreiros na região metropolitana de Belém; no entanto, o projeto de pesquisa "Religião e política entre afrorreligiosos na Amazónia", localizou na mesma cidade apenas trinta terreiros organizados em forma de associações civis; destes, cerca de quinze são realmente atuantes na militância política (Cordovil, 2014).

Dentre estas lideranças atuantes, algumas se envolvem com movimentos de mulheres. Em 2012, a Conferência Estadual de Mulheres, realizada em Belém, contou com a presença de nove delegadas afrorreligiosas. Existem também alguns terreiros com projetos políticos e sociais voltados para mulheres. Porém, de maneira geral, a maior militância dos afrorreligiosos é pela liberdade religiosa. As religiões afro-brasileiras foram duramente perseguidas pelo Estado no Brasil até à promulgação da Constituição de 1988, que estabelece a liberdade religiosa como princípio constitucional. Atualmente, apesar da liberdade jurídica, os adeptos dessas religiões não deixaram de ser perseguidos pelos evangélicos neopentecostais que instituem uma "guerra santa" contra essas religiões, realizando ataques a templos e fiéis e uma verdadeira ofensiva mediática nos meios de comunicação de massa (Silva, 2007).

Além da luta pela liberdade religiosa, a participação em movimentos sociais que buscam políticas públicas de saúde, segurança alimentar, cultura e igualdade racial ocupa espaço importante na agenda política dos afrorreligiosos. Com base no facto de se tratar de uma religião que possui forte conteúdo étnico e de resistência cultural, os líderes das religiões afro-brasileiras têm pleiteado junto ao Estado a inclusão em diversas políticas públicas. Em 2013, foi aprovado um Plano de Desenvolvimento para as Comunidades Tradicionais de Matriz Africana que prevê a inclusão social dos terreiros a partir de políticas públicas de saúde, cultura, segurança alimentar, etc. Nessas lutas, há forte presença de mulheres, reconhecidas por conta da tradicional imagem que associa os terreiros de candomblé no Brasil como espaços liderados por mulheres negras, de idade avançada. Este imaginário se perpetuou no Brasil por meio da literatura, da música popular, do cinema e da televisão. ${ }^{5}$

\footnotetext{
${ }^{5}$ Existem músicas de Caetano Veloso e de Elis Regina exaltando as virtudes de famosas mães de santo do candomblé da Bahia. As obras do escritor baiano Jorge Amado também destacam a predominância das mães de santo nos terreiros.
} 
Por causa da liderança que possuem dentro dos terreiros, as mães de santo são convidadas a dialogar com gestores de políticas públicas, a integrar conselhos e outras funções públicas. Para os agentes governamentais seria contraditório que as mulheres, enquanto maiores líderes dos templos, não dialoguem diretamente com eles, pelo que lentamente a cultura dos ogãs vem desaparecendo. As mulheres que são líderes de terreiro têm uma agenda movimentada de encontros, reuniões e conferências, aprendem a linguagem técnica dos burocratas e gestores. As mães de santo são as grandes protagonistas dessas lutas, que também visualizam como parte de seu sacerdócio. $\mathrm{Na}$ fala da sacerdotisa Mãe Nalva, "Meu trabalho social e de militância é também um trabalho para o Orixá". ${ }^{6}$

$\mathrm{Na}$ wicca, tanto os sacerdotes quanto as sacerdotisas de maior projeção social estão engajados em lutas políticas e de militância. Assim como no candomblé, esta militância é mais forte e direcionada para os debates públicos que dizem respeito à liberdade religiosa e à defesa do Estado laico. ${ }^{7}$ Entre as mulheres, algumas envolvem-se com movimentos feministas e consideram que as próprias atividades litúrgicas de wicca contribuem para a propagação de uma visão de mundo feminista. $\mathrm{Na}$ fala da sacerdotisa Danna Myr, coordenadora do Círculo de Mulheres em Belém:

Também esse círculo, ele faz parte da minha militância [...] O que eu faço no círculo de mulheres é uma partilha daquilo que eu fazia na minha vida diária [...] A minha vida religiosa, ela é a extensão, ela se estende dentro de todos os movimentos que eu participo, porque eu sou sacerdotisa em todos eles [...] e todo mundo percebe porque é a fala da Deusa. Nossas atuações são pra moldar a realidade que não concordamos, que achamos injusto, e esses espaços são os espaços em que eu consigo estender a minha postura, a minha decisão de ser sacerdotisa. ${ }^{8}$

É importante ressaltar que o Círculo de Mulheres é uma atividade pública promovida pela Abrawicca, sendo aberto a mulheres de qualquer religião.

Como se pode depreender destas falas, para as lideranças da wicca, assim como para as mães de santo do candomblé, seu sacerdócio é uma militância, e para elas, o religioso e o político estão interligados. Desta forma, por serem empoderadas dentro das suas comunidades religiosas, essas mulheres encontram ali as bases de uma militância pública, que ocorre

\footnotetext{
${ }^{6}$ Entrevista concedida em 10.09.2012.

7 A líder da Tradição Diânica do Brasil, Mavésper Cy Ceridwen, é advogada e faz parte da Comissão criada pela Secretaria de Direitos Humanos no Brasil para defesa da diversidade religiosa e do Estado laico (Terzetti Filho, 2014).

${ }^{8}$ Entrevista pessoal concedida em 14.03.2015.
} 
não só em favor dos direitos da mulher, mas em defesa dos direitos de seus grupos religiosos.

\section{Considerações finais}

Nas práticas de candomblé e wicca estudadas em Belém, na Amazônia, a mulher e o feminino são valorizados de maneira própria, dentro dos limites culturais destes grupos e da sociedade local. Apesar dos princípios cosmológicos e políticos que embasam a wicca e o candomblé possuírem algumas semelhanças, a forma como os adeptos de cada uma dessas religiões vivenciam o feminismo e se engajam na militância é bastante diferente.

Entre lideranças da wicca existem muitos discursos e práticas ligados ao feminismo e à valorização da mulher, algumas são engajadas com movimentos sociais, outras acreditam que suas atitudes na vida privada podem mudar a sociedade. Já nas religiões afro-brasileiras, o principal foco de militância política é o reconhecimento da religião como património étnico e cultural brasileiro e a plena liberdade religiosa. No interior dessas lutas tem ocorrido grande empoderamento das mulheres religiosas, que são suas maiores protagonistas. A politização dos terreiros, que vem sendo alvo de políticas públicas desde o início dos anos 2000, levou as sacerdotisas para a rua, engajadas em lutas políticas e sociais, o que vem contribuindo para a desconstrução da tradicional relação entre mulheres e espaço privado, anteriormente existente nessas comunidades religiosas.

Apesar de numericamente pouco expressivas no universo geral da população brasileira, ambas as religiões estão entranhadas no imaginário e na cultura do país. O candomblé foi percebido desde o final do século XIX por pesquisadores e intelectuais como um locus privilegiado de persistência da cultura africana no Brasil. As atuais políticas públicas e ações afirmativas direcionadas à população negra no Brasil possuem impacto e recebem forte influência deste universo religioso.

A wicca, apesar de ser uma religião historicamente recente no Brasil e no mundo, tem grande visibilidade na mídia, nas artes e na literatura, especialmente no mercado de livros esotéricos, com vários títulos já publicados por autores brasileiros (Prieto, 2013; Ceridwen, 2003). O imaginário das bruxas e dos bruxos povoa a mente dos jovens e atrai muitos para a prática da religião.

Por estes motivos, discussões promovidas por líderes de religiões com tais características contribuem para uma pluralização dos debates a respeito de padrões de família e papéis de gênero no Brasil. Suas lideranças apresentam-se na esfera pública fazendo proposições e ganhando visibilidade. Por outro lado, suas cosmovisões e vivências religiosas, quando praticadas mesmo que 
por pequenas coletividades, contribuem para a formação de cidadãos mais conscientes e críticos com relação às diversas formas de opressão de gênero.

A construção dessas lutas na Amazônia e no Brasil contribui para a pluralização dos feminismos. Suas práticas devem ser analisadas levando em conta uma sociologia das ausências, que tende a tornar menos significativas ou a invisibilizar as lutas sociais que acontecem no Sul Global. Segundo Boaventura de Sousa Santos: "A experiência social em todo o mundo é muito mais variada do que a tradição científica e filosófica ocidental conhece e considera importante" (Santos, 2002: 238).

A partir de uma análise que tenha como foco a ampliação do conhecimento sobre experiências e formas de resistências elaboradas para além do marco tradicional da razão ocidental, proponho a compreensão do candomblé e da wicca construídos na Amazônia como formas de espiritualidades feministas. Seus feminismos estão contidos na maneira como promovem o empoderamento da mulher no espaço privado das comunidades religiosas e também nos espaços públicos de militância, assim como pela forma como estas comunidades religiosas descontroem padrões patriarcais de família.

Esta proposição possui caráter apenas exploratório e novos estudos precisam ser desenvolvidos no interior destes grupos religiosos no Brasil, para melhor compreender de que forma eles constroem suas lutas e práticas, assim como de que maneira adaptam e reinventam as referências trazidas de fora.

\section{Referências bibliográficas}

Adler, Margot (2006), Drawing Down the Moon: Witches, Druids, Goddess-Worshippers, and Other Pagans in America Today. New York: Penguim [5. ${ }^{\mathrm{a}}$ ed.].

Augrás, Monique (2008), O duplo e a metamorfose: a identidade mítica em comunidades Nagô. Petrópolis: Vozes.

Bastos, Ivana Silva (2009), "A visão do feminino nas religiões afro-brasileiras", CAOS - Revista Eletrônica de Ciências Sociais, 14, 156-165.

Bastide, Roger (2001), O candomblé da Babia. São Paulo: Companhia das Letras.

Bezerra, Karina Oliveira (2012), A wicca no Brasil: adesão e permanência dos adeptos na região metropolitana do Recife. Dissertação de mestrado apresentada à Universidade Católica de Pernambuco, Recife, Brasil.

Birman, Patrícia (1991), "Relações de gênero, possessão e sexualidade", PHISYS, Revista de Saúde Coletiva, 1(2), 37-57.

Birman, Patrícia (1995), Fazer estilo criando gêneros. Possessão e diferenças de gênero em terreiros de umbanda e candomblé no Rio de Janeiro. Rio de Janeiro: Edições UERJ/ /Relume Dumará. 
Braidotti, Rosi (2001), "Becoming a Woman: Rethinking the Positivity of Difference”, in Elisabeth Bronfen; Misha Kavka (orgs.), Feminist Consequences: Theory for the new century. New York: Columbia University Press, 381-413.

Brasil (2011), Alimento: direito sagrado. Pesquisa socioeconómica e cultural de povos e comunidades tradicionais de terreiros. Brasília: MDS, Secretaria de Avaliação e Gestão da Informação.

Ceridwen, Mavésper Cy (2003), Wicca Brasil: guia de rituais das deusas brasileiras. São Paulo: Gaia.

Chifton, Chas; Harvey, Graan (2004), The Paganism Reader. New York: Routledge.

Christ, Carol. P. (1979). "Why Women Need the Goddess: Phenomenological, Psychological, and Political Reflections”, in Carol Christ; Judith Plaskow (orgs.), Woman Spirit Rising: A Feminist Reader in Religion, 273-287.

Cordovil, Daniela (2013), "Sexualidade, gênero e poder: uma análise da participação feminina em políticas públicas para afrorreligiosos em Belém, Pará”, PLURA, Revista de Estudos de Religião, 4(2), 149-163.

Cordovil, Daniela (2014), Religiões afro: introdução, associação e políticas públicas. São Paulo: Fonte Editorial.

Cordovil, Daniela (2015), "O poder feminino nas práticas da wicca: uma análise dos “Círculos de Mulheres'”, Estudos Feministas, 23(2), 431-449.

Eller, Cynthia (1995), Living in the Lap of the Goddess: The Feminist Spirituality Movement in America. Boston: Beacon Press.

Eller, Cynthia (2000), "White Women and the Dark Mother", Religion, 30(4), 367-378.

Ferreti, Sérgio (2009), Querebentã de Zomadonu. Etnografia da Casa das Minas do Maranhão. Rio de Janeiro: Pallas [3. a ed.].

Fry, Peter (1982), "Homossexualidade masculina e cultos afro-brasileiros", in Peter Fry, Para inglês ver: identidade e política na cultura brasileira. Rio de Janeiro: Zahar, 54-86.

Geertz, Clifford (1978), A interpretação das culturas. Rio de Janeiro/RJ: Zahar editores.

Guerriero, Silas (2006), Novos movimentos religiosos: o quadro brasileiro. São Paulo: Paulinas.

Hutton, Ronald (1995), The Triumph of the Moon: A History of Modern Pagan Witchcraft. Oxford Paperbacks: New Ed Edition.

Landes, Ruth (1940), “A Cult Matriarchate and Male Homosexuality”, Journal of Abnormal and Social Psychology, 35, 386-397.

Landes, Ruth (2002), A cidade das mulheres. Rio de Janeiro: Ed. UFRJ.

Matory, J. Lorand (2005), Black Atlantic Religion: Tradition, Transnationalism, and Matriarchy in the Afro-Brazilian Candomblé. Princeton: Princeton University Press.

Oxóssi, Stella de (2015), “Entrevista com Mãe Stella de Oxóssi”, blogue Histórias do Povo Negro, de 6 de janeiro de 2001. Consultado a 13.07.2015, em https://historiasdopovonegro.wordpress.com/fe-2/no-candomble-e-a-gente-que-se-supera-nao-tem-que-superar-o-outro-entrevista-com-mae-stella-de-oxossi/. 
Pereira, Nunes (1979), A Casa das Minas: contribuição ao estudo das sobrevivências do culto dos Voduns, do panteão Daomeano, no Estado do Maranbão. Petrópolis: Vozes [2. ${ }^{\mathrm{a}}$ ed.].

Pike, Sarah (2004), New Age and Neopagan Religions in America. New York: Columbia University.

Prieto, Claudiney (2013), Wicca para todos. São Paulo: Alfabeto.

Rodrigues, Raimundo Nina (2004), Os africanos no Brasil. Brasília: Ed. UNB.

Rountree, Kathryn (2005), "Goddess Spirituality and Nature in Aotearoa New Zealand”, Pomegranate: International Journal of Pagan Studies, 7(2), 141-156.

Salomonsen, Jone (2002), Enchanted Feminism: The Reclaiming Witches of San Francisco. London/New York: Routledge.

Segato, Rita (2005), Santos e daimones. O politeísmo afro-brasileiro e a tradição arquetipal. Brasília: Ed. UNB [2. ${ }^{a}$ ed.].

Santos, Boaventura de Sousa (2002), "Por uma sociologia das ausências e uma sociologia das emergências”, Revista Crítica de Ciências Sociais, 63, 237-280.

Silva, Vagner Gonçalves da (2007), "Entre a Gira de Fé e Jesus de Nazaré: relações socioestruturais entre neopentecostalismo e religiões afro-brasileiras", in Vagner Gonçalves da Silva (org.), Intolerância religiosa. Impactos do neopentecostalismo no campo religioso afro-brasileiro. São Paulo: Edusp, 191-260.

Tamayo, Juan (2011), "Las mujeres en las religiones", in Margarita Pintos de Cea-Naharro (org.), Las mujeres en las religiones. Madrid: Ediciones Civilización Global, 2-19.

Terzetti Filho, Celso Luís (2014), “A institucionalização da wicca no Brasil: entrevista com a bruxa wiccaniana Mavesper Cy Ceridwen”, REVER, 14(2), 279-290.

Artigo recebido a 29.07.2015

Aprovado para publicação a 06.05.2016

\section{Daniela Cordovil}

Universidade do Estado do Pará

Rua do Una, n. ${ }^{\circ}$ 156, Belém, Pará, 66.050-540 Telégrafo, Brasil

Contato: daniela.cordovil@gmail.com 


\section{Feminist Spirituality:}

Gender Relationships and Family Patterns among Wicca and Candomblé Practitioners in Brazil

This paper presents a comparative study between two religions - wicca and candomblé - whose rituals and practices enable women's empowerment and promote the Sacred Feminine. The ethnographic field research conducted in Belem, Brazil, between 2011 and 2015, reveals that these religions' worldviews contain elements that promote their members' feminist practices. The paper explores the gender relations and family patterns built within these two religious groups in order to show how their practices contribute to the empowerment of women. The ethnographic analysis serves as the basis for a preliminary discussion on whether or not it is possible to analyze these religions using the concept of feminist spiritualities. Keywords: family; feminism; gender relations; religion; sacred feminine.

\section{Spiritualités féministes:} Relations de genre et modèles familiaux parmi les adeptes de la wicca et du candomblé au Brésil

Ce texte présente une étude comparative entre deux religions dont les rites et les pratiques permettent la mise en valeur de la femme et du sacré féminin, la wicca et le candomblé. À partir de recherche de terrain ethnographique réalisée à Belém, Brésil, entre 2011 et 2015, nous présenterons des éléments de la cosmovision de ces religions qui corroborent des pratiques féministes de la part de leurs adeptes. Le texte se penchera sur les rapports de genre et les modèles familiaux élaborés dans le cadre de ces deux groupes religieux, dans le but de montrer combien leurs pratiques contribuent à la mise en valeur de la femme. À partir de cette analyse ethnographique, nous engagerons un débat préliminaire portant sur la possibilité ou pas d'analyser ces cultes à partir du concept de spiritualités féministes.

Mots-clés: famille; féminisme; relations de genre; religion; sacré féminin. 